\title{
MAPEAMENTO E PERFIL DA PESQUISA CIENTÍFICA EM DESIGN NO BRASIL: UM ESTUDO DOS PROGRAMAS DE PÓS-GRADUAÇÃO
}

\author{
Rafael Gutierres Castanha ${ }^{1}$, Guilherme Oliveira Pironi ${ }^{2}$ \\ ${ }^{1}$ Universidade Estadual Paulista - UNESP, Marilia, SP. ${ }^{2}$ Universidade do Oeste Paulista - UNOESTE, Presidente \\ Prudente, SP. E-mail: r.castanha@gmail.com, guilhermepironi@unoeste.br
}

\section{RESUMO}

Esta pesquisa buscou mapear e traçar o perfil do Design enquanto área do conhecimento no Brasil por meio dos seus atuais programas de pós-graduação, observando os principais centros de pesquisa e de formação de novos cientistas, que futuramente darão continuidade na formação de novos pesquisadores. Para tal, foram recuperados os dados (públicos) presentes na plataforma Sucupira vinculada ao Coordenação de Aperfeiçoamento de Pessoal de Nível Superior referente ao último quadriênio de avaliação (2013-2016). Conclui-se que atualmente o Design enquanto área do conhecimento desenvolve-se de maneira mais intensa nas regiões sul e sudeste e possui como principais expoentes de pesquisa a UNESP/Bauru e a Universidade Anhembi Morumbi, ambas situados no estado de São Paulo.

Palavras-chave: Design, Mapeamento Científico, Pós-graduação

\section{MAPPING AND PROFILE OF DESIGN SCIENTIFIC RESEARCH IN BRAZIL: A STUDY OF POSTGRADUATE PROGRAMS}

\begin{abstract}
This research aimed to map and outline the profile of Design as an area of knowledge in Brazil through its current graduate programs, observing the main centers of research and education of new scientists, which in the future will continue the education of new researchers. To this end, the (public) data on the Sucupira platform linked to the Coordenação de Aperfeiçoamento de Pessoal de Nível Superior for the last four years of evaluation (2013-2016) were retrieved. It is concluded that currently the Design as knowledge area develops more intensely in the south and southeast regions and has as main research exponent the UNESP / Bauru and Anhembi Morumbi University, both located in the state of São Paulo.
\end{abstract}

Key-word: Design, Scientific Mapping, postgraduate programs

\section{INTRODUÇÃO}

Atualmente o Design parece estar associado a uma espécie de interface na relação entre o homem e o significado de seus objetos, onde a posse destes acarreta um conjunto de representações cuidadosamente pensadas por seu projetista, o Designer (CARÁ, 2008).

Tais conceitos tem relação direta da revolução industrial onde o panorama mudou da produção feita pelas mãos do artesão para uma produção feita através de máquinas, buscando atingir o máximo possível de pessoas, levando assim à simplificação das formas para que fossem replicáveis e, segundo Azevedo (2017), à criação de uma necessidade com relação à funcionalidade, não bastando mais ao objeto ser somente belo, mas também, funcional e relevante.

Seguindo a tendência internacional de alavancar o Design através da indústria, a atividade (na época ainda tratada na maioria das vezes como Desenho Industrial) passa a ganhar visibilidade no Brasil a partir do incentivo à industrialização promovido pelo então presidente Getúlio Vargas e posteriormente por seu sucessor Juscelino Kubitschek por volta dos anos de 1950

Enquanto disciplina, o Design viria a ganhar seu primeiro centro de formação com nível universitário apenas em 1963 com a abertura da ESDI - Escola Superior de Design Industrial, no Rio de Janeiro. Segundo Cará (2008), tanto a indústria quanto a academia 
adotavam a prática do Design concebida nos moldes do funcionalismo alemão, advindos das famosas escolas de Design da Bauhaus e Ulm.

A partir dos anos 1970 é revista a nomenclatura Desenho Industrial em favor da palavra Design, movimento ocorrido a partir do questionamento da abordagem quase puramente voltada para a produção industrial em favor de uma visão que leve em conta também fatores sociais, políticos, econômicos e culturais do país no desenvolvimento dos projetos. Desde então ficam em aberto as diversas possibilidades de posicionamento do profissional de Design onde, segundo Cará (2008), é legitimo tanto o favorecimento do individualismo egoísta do profissional até a prática em prol do coletivo a qual atenta às problemáticas sociais do meio onde está inserido esse indivíduo.

Uma vez atingido tal patamar de relevância industrial, acadêmica e social, começam a aparecer as primeiras associações dos Designers pelo país como a Associação dos Profissionais em Design do Rio Grande do Sul (APDesign) em 1987 e a Associação dos Designers Gráficos (ADG) em 1989, o que abre precedente para investimentos no contínuo aperfeiçoamento da área.

Sendo assim, em 1994 que o Brasil ganha seu primeiro curso de pós-graduação em Design, oferecido pela Pontifica Universidade Católica do Rio de Janeiro (PUC-RJ). A criação deste curso representou um marco no desenvolvimento de novas competências acadêmicas Design, além de um incentivo para outras instituições seguirem o mesmo rumo nesta modalidade de ensino e formação (TRISKA; VELA; DOLZAN; 2014), dando então inicio ao avanço das pesquisas da área e consolidando-a como importante área do conhecimento no país.

Destaca-se o surgimento dos programas de pós-graduação da área, pois, o progresso da ciência brasileira tem forte relação com a produção tecnológica e científica destes programas das mais diversas áreas do conhecimento. Dessa maneira, diversos estudos cientométricos (que avaliam a ciência) têm ganham notoriedade visto e contribuem diretamente para a análise da evolução científica e tecnológica do país, além de auxiliar futuras pesquisas por meio de indicadores sobre diversos assuntos e temáticas, aportando o planejamento e tomada de decisões educacionais, sociais e econômicas (MORAES, GIROLDO, 2012).
Dessa maneira, o objetivo central desta pesquisa foi mapear e traçar o perfil do Design enquanto área do conhecimento no Brasil por meio dos seus atuais programas de pósgraduação, observando os principais centros de pesquisa e de formação de novos cientistas, que futuramente darão continuidade na formação de novos pesquisadores. Para tal, serão utilizados os dados (públicos) presentes na plataforma Sucupira vinculada ao Coordenação de Aperfeiçoamento de Pessoal de Nível Superior (CAPES) referentes ao último quadriênio de avaliação (2013-2016).

\section{DESENVOLVIMENTO TEÓRICO DESIGN ENQUANTO ÁREA DO CONHECIMENTO}

Para os fins do presente artigo trataremos do Design a partir das definições que gerem menos ambiguidade entre seus autores onde o Design é caracterizado pela atribuição de configuração material a conceitos intelectuais por meio de conhecimentos multidisciplinares aplicados às ferramentas disponíveis para realização de tal feito, configurando então uma maneira de criar interfaces lógicas entre a produção industrial, a sociedade urbana atual e a integração global dos povos - ou globalização para resultar num grande meta-processo integrador entre a identificação de necessidades e a busca por soluções (CARDOSO, 2008).

Apesar do Design não estar relacionado unicamente à produção industrial, a definição de 'Industrial Design' cunhada pelo Comitê de Práticas Profissionais e adotada pela WDO World Design Organization serve de suporte à afirmação anterior ao dizer que "Design Industrial é um processo estratégico de solução de problemas que incentiva inovação, constrói sucesso nos negócios e leva ao aumento da qualidade de vida através de produtos, sistemas, serviços e experiências inovadores" (WDO, 2015).

\section{A PÓS-GRADUAÇÃO NO BRASIL E SUAS CONTRIBUIÇÕES CIENTÍFICAS}

A pós-graduação brasileira, na modalidade stricto senso, iniciou-se tardiamente no Brasil a partir da criação da A Coordenação de Aperfeiçoamento de Pessoal de Nível Superior (CAPES) em 1951, como entidade vinculada ao Ministério da Educação (MEC) (CIRANI; CAMPANÁRIO; SILVA, 2015) e com o parecer no995 de 1965 que regulamentou o funcionamento da pós-graduação no Brasil (WASSEM; PEREIRA; BALZAN; 2015). 
A CAPES e o MEC estimam em seu último estudo oficial, que o Brasil possuía 516.983 mestres e 184.354 doutores titulados em 2014, totalizando 701337 pós-graduados. E mais, somente em 2016, o Brasil ganhou 73549 novos mestres e doutores (CAPES, 2017).

Nesse sentido, nota-se a procura pelo aperfeiçoamento científico de profissionais de diversas áreas e o interesse de contribuir com o desenvolvimento científico e tecnológico do país. Observa-se, então, o surgimento de diversas políticas públicas focadas nas universidades como parte fundamental e central não apenas da pósgraduação, mas da ciência brasileira. Tais fatos contribuem para o aumento de cursos de pósgraduação em diversas áreas do conhecimento aportando o progresso científico e tecnológico no país (LETA, 2011).

Analisar o Design, especificamente, por meio de seus programas de pós-graduação, darão diretrizes e perspectivas futuras do desenvolvimento científico, técnico e tecnológico da área, além de apontar os principais centros que debatem e mais influenciam a área.

\section{METODOLOGIA}

A preocupação e o constante debate com a distribuição geográfica dos programas pósgraduação no Brasil traz consigo questionamento em relação as diferenças e similaridades das diversas regiões, implicando na formulação e execução de políticas públicas voltadas ao desenvolvimento educacional e científico do país (MORAES; GIROLDO, 2012), principalmente quando associados a indicadores de desenvolvimento social e econômico.

Nesse sentido, a fim de traçar o perfil e mapear do Design enquanto área do conhecimento esta pesquisa configura-se como uma análise cientométrica da área de Design e apoiou-se em dados públicos da CAPES e da Plataforma Sucupira de avaliação de programas de pós-graduação (disponíveis publicamente em seus portais eletrônicos). Esta pesquisa desenvolveu-se nas seguintes etapas: 1) Levantamento dos programas de pós-graduação em Design juntamente com as instituições as quais estão vinculados; 2) Identificação dos estados e regiões onde as instituições se localizam; 3) recuperação de dados específicos de cada programa (nível de aperfeiçoamento ofertados - mestrado, mestrado profissional e/ou doutorado -, nota da última avaliação quadrienal da CAPES e produções bibliográficas e técnicas); 4) Mapeamento e elaboração do perfil do Design sob a perspectiva científica no Brasil.

\section{APRESENTAÇÃO DOS RESULTADOS}

Atualmente a CAPES avalia (com notas de 3 a 7) as diversas áreas do conhecimento segundo uma hierarquia específica e definida. A instituição reconhece 49 áreas de avaliação dividida em dois níveis: os Colégios (divididos em Ciências da Vida, Ciências Exatas, Tecnológicas e Multidisciplinar e Colégio das Humanidades) e as Grandes Áreas (Ciências Agrárias, Biológicas, da Saúde, Ciências exatas e da terra, engenharias, multidisciplinar, ciências humanas, sociais aplicadas e linguísticas, letras e artes). Ou seja, três colégios e nove grandes áreas, onde estas grandes áreas dividem-se nas 49 subáreas.

Especificamente o Design, encontra-se situado no colégio das Humanidades, na grande área Ciências Sociais Aplicadas e na subárea Arquitetura, Urbanismo e Design. Nesse sentido, recuperou-se o relatório de avaliação desta subárea e filtrou-se apenas os cursos denominados Design. Para conhecimento, esta subárea possui 59 programas de pós-graduação dos quais 19 são denominados como Design.

Ao recuperar estes 19 programas, foram identificadas as instituições os quais estão vinculados, os estados, os níveis de aperfeiçoamento ofertados, notas de avaliação e produções científicas (bibliográficas e técnicas), assim como apresentado na Figura 1.

\section{DISCUSSÃO}

Nota-se que 11 dos 19 programas (58\%) oferecem cursos de Mestrado e Doutorado simultaneamente. Outros oito programas oferecem apenas cursos de mestrado, sendo que quatro deles $(21 \%)$ são de nível stricto senso (mestrado acadêmico) e os outros quatro de nível latu senso (mestrado profissional). 
Figura 1. Programas de pós-graduação em Design no Brasil

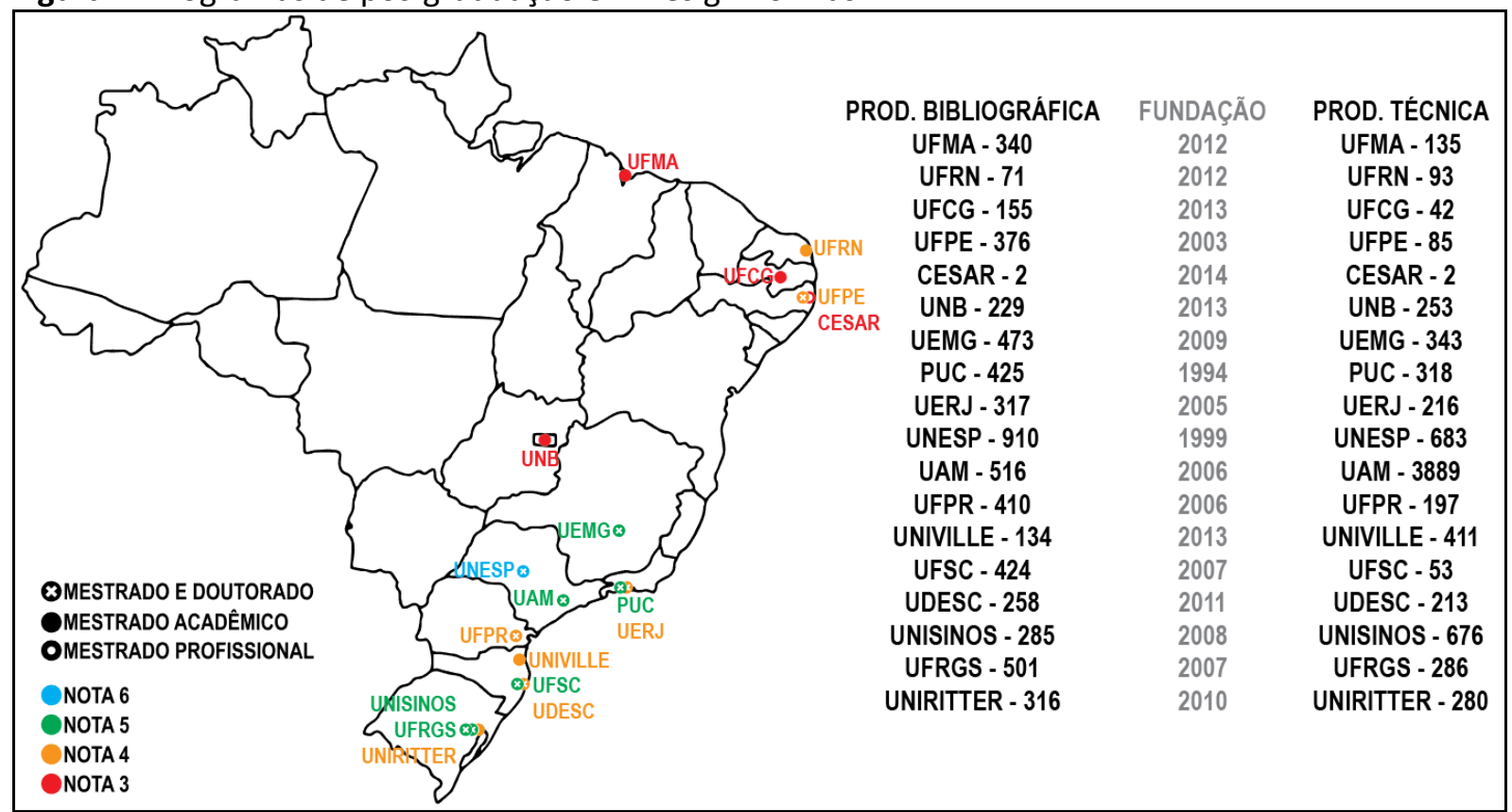

*dados referentes a última avaliação quadrienal da CAPES (2013-2016) e plataforma Sucupira

Destaca-se, que dentre os programas que oferecem cursos de mestrado e doutorado, cinco são situados na região Sudeste (PUC, UNESP/Bauru, UERJ, UAM, UEMG) com apresentado na Figura 1. Dentre estas, a UNESP/Bauru possui melhor avaliação segundo a CAPES, com a nota 6 , seguida pela PUC-RJ, UAM e UEMG com notas 5 e UERJ com nota 4.

Observou-se também, que outros cinco programas se situam na região sul do Brasil (UFPR, UFSC, UNISINOS, UDESC, UFRGS), onde a UFSC, UNISINOS e UFRGS são as melhore avaliadas, como nota 5, seguido da UFPR e UDESC com nota 4. Esta análise deixa claro que os programas de pós-graduação se encontram no eixo sul-sudeste, corroborando com também com os maiores índices de desenvolvimento econômico do país. Porém, destes 19 programas, um destes está situado na região nordeste (UFPE), confirmando a alta concentração na região sul-sudeste.

Já com relação a produção científica (bibliográfica e técnica), a UNESP/Bauru destacase mais uma vez como a mais produtiva, com 910 produções bibliográficas e 683 produções técnicas, consolidando-se como o programa de pós-graduação mais relevante do país. Ressaltase ainda, como programas de alta produtividade os vinculados a UAM com 516 produções bibliográfica e 3889 produções técnicas e a UFRGS com 501 produções bibliográficas e 286 produções técnicas. Ademais, a UNESP/Bauru extrapola as fronteiras nacionais e promove um intercambio e relações diretas com outros países, esta internacionalização é um dos requisitos para que o programa receba a nota 6 .

Dentre os demais programas, que oferecem apenas cursos de mestrado (acadêmico ou profissional), que apenas um localiza-se na região sudeste (UNIFATEA), enquanto quatro situam-se na região nordeste (UFMA, UFCG, UFRN, CESAR) juntamente com dois programas na região sul (UNIVILLE, UNIRITTER) e um no Distrito Federal (UNB).

Estes programas, podem ser considerados menos expressivos pelas notas de avaliação dos mesmos (notas 3 e 4), entretanto, são cursos com grande potencial de evolução, visto que alguns possuem bons níveis de produção, como no caso da UFMA com 340 produções bibliográficas e a UNIVILLE com um alto de número de produções técnicas, num total de 411.

Ao retornar esta análise sob o olhar geográfico, constou-se, que apenas dez dos 26 estados possuem algum tipo de programa de pósgraduação em Design. Numa perspectiva regional, apenas a região Norte do país não possui programas de pós-graduação na área. Tal fato representa uma dificuldade eminente do desenvolvimento científico da área nesta localidade, entretanto, deve-se levar em conta que o Design ainda pode ser considera uma área do conhecimento emergente, comparada com áreas mais tradicionais como Matemática, 
Filosofia, Engenharias, Ciências Médicas, Pedagogia e etc.

Tal fato corroborará com a forte relação entre o ano de fundação dos programas e suas produções e nota de avaliação, isto é, os programas mais antigos, possuem maior nota de avaliação e níveis maiores de produção científica, já os programas mais novos, possuem as menores notas e menor número de produções.

\section{CONSIDERAÇÕES FINAIS}

Esta pesquisa mapeou e traçou e perfil do Design enquanto área do conhecimento científico por meio dos documentos de avaliação da CAPES individualizando-a, isto é, analisou-se única e exclusivamente os programas de pós-graduação em Design e não toda a grande área composta por Arquitetura, Urbanismo e Design, trazendo um olhar mais profundo e singular da área apontando a predominância das áreas sudeste e sul com relação ao desenvolvimento científico da área.

Por fim, esta pesquisa pretende também, servir como diretriz para discentes e docentes que ingressam e egressam da área do Design todos os anos, apontando os principais centros de pesquisa onde os mesmos poderão aperfeiçoar-se cada vez mais. Além disso, aportar futuras pesquisas científicas e possíveis desenvolvimentos de políticas públicas que beneficiem a área.

\section{REFERÊNCIAS}

AZEVEDO, W. O que é Design. São Paulo: Brasiliense, 2017.

CAPES - COORDENAÇÃO DE APERFEIÇOAMENTO DE PESSOAL DE NÍVEL SUPERIOR. Comissão especial de acompanhamento do PNPG-20112020. Brasília: CAPES, 2017.

CAPES - COORDENAÇÃO DE APERFEIÇOAMENTO DE PESSOAL DE NÍVEL SUPERIOR. Relatório de Avaliação Quadrienal 2017 - Arquitetura, Urbanismo e Design. Brasília: CAPES, 2017.

CAPES - COORDENAÇÃO DE APERFEIÇOAMENTO DE PESSOAL DE NÍVEL SUPERIOR. Plataforma sucurpira. Brasília: CAPES, 2018. Disponível em: <www.capes.gov.br/plataforma-sucupira>. Acesso em: 16 jul. 2018.

CARÁ, M. S. Do desenho industrial ao Design no Brasil: uma bibliografia crítica para a disciplina.
2008. Dissertação (Mestrado em Design e Arquitetura) - Faculdade de Arquitetura e Urbanismo, Universidade de São Paulo, São Paulo, 2008.

CIRANI, C. B. S; CAMPANARIO, M. A.; SILVA, H. M. $A$ evolução do ensino da pós-graduação senso estrito no Brasil: análise exploratória e proposições para pesquisa. Avaliação, v. 20, n. 1, p. 163-187, 2015.

LETA, J. Indicadores de desempenho, ciência brasileira e a cobertura das bases informacionais. Rev. USP, São Paulo, n. 89, 2011.

MORAES, M. H. M.; GIROLDO, D. Mapeamento da pós-graduação e estudo cientométrico da área da educação. Encontro Brasileiro de Bibliometria e Cientometria, v. 3, p. A26, 2012.

TRISKA, R.; VELA, J. C.; DOLZAN, J. E. A pósgraduação stricto sensu do Design no Brasil: uma leitura. Estudos em Design, v. 22, n. 3, p. 70-80, 2014.

WASSEN, J.; PEREIRA, E. M.; BALZAN, N. C. Política de avaliação em programas de pósgraduação de excelência em educação. Atos de Pesquisa em Educação, v. 1, n. 10, p. 215-243, $2015 . \quad$ https://doi.org/10.7867/18090354.2015v1n10p215-243

WDO - WORLD DESIGN ORGANIZATION. Constitution \& By-Laws. Gwangju, Córeia do Sul. 2015. Disponível em: <http://wdo.org/wpcontent/uploads/2017/02/WDO_ Constitution.pdf>. Acesso em: 21 jul. 2018.

Recebido para publicação em 30/03/2018

Revisado em 10/08/2018

Aceito em 28/08/2018 